\title{
On Winners and Losers in Procurement Auctions
}

\author{
Gregory (Grzegorz) E. Kersten \\ InterNeg Research Centre \\ Concordia University \\ Montreal, Canada \\ gregory@jmsb.concordia.ca
}

\author{
Tomasz Wachowicz \\ Department of Operations Research \\ University of Economics \\ Katowice, Poland \\ tomasz.wachowicz@ae.katowice.pl
}

\begin{abstract}
The use of auctions in procurement results in price reduction as well as the reduction in the cost and the time required to complete transactions. In many situations, priceonly auctions resulted in the violation of the contracts or even contractors' bankruptcies. This is one reason for the introduction of multi-attribute auctions as well as auctionsfollowed-by negotiations. Auction theory is based on two assumptions which assure that auctions are efficient mechanisms, guarantee efficient solutions, and produce the best possible results for bid-takers. In practice these assumptions are often violated. The contribution of this paper is to propose a procedure for auctions-followed-by negotiations which retains important auction features such as process transparency and efficiency while allowing for increased social welfare. The unique feature of the procedure is the introduction of the winwin phase in which the market participants may attempt to make joint improvements to efficient solutions obtained from auctions.
\end{abstract}

\section{INTRODUCTION}

G overnment-to-business (G2B) and business-to-business (B2B) online revers auctions have been introduced in mid-1990s to complement the paper-based submissions. They have become a popular way to source products and services a few years after their introduction, $25 \%$ of total purchasing was done using these auctions [1]. Their use resulted in price reduction as well as the reduction in costs and time required to complete transactions. Other benefits attributed to these auctions include the creation of new markets, increased participation of suppliers, increased transaction transparency and price visibility, and increased standardization and efficiency of purchasing $[2,3]$. These advantages have been contrasted with such disadvantages as collusion, opportunism and coercion [4]. However, these drawbacks are not limited to the auction mechanisms. Catalogues and negotiations have been also found prone to collusion, coercion and opportunism as well as deceit and threats.

Many of the negative, often illegal, aspects of market mechanisms can be addressed through the imposition of or-

This work has been supported by the grants from the Natural Sciences and Engineering Research Council of Canada (NSERC) and Concordia University. ganizational and legal frameworks. Organizational framework may be used to enforce transparency, information disclosure, and standardization. Laws can be used to make collusion and coercion difficult as investigations uncover criminal behavior, for example such as bids rigged by Montreal Mafia, which controlled most of road contracts [5].

The underlying theory of the exchange mechanisms appears to favor auctions. Bulow and Klemperer [6] in one of the first comparative studies of auctions and negotiations prove that given a choice between auctions with $n+1$ bid-makers and negotiations with $n$ negotiators the bid-maker should always choose an auction. This implies that the value of increased competition in auctions exceeds the negotiator's skill and prowess.

There are three key conditions which need to be met in order for the exchange mechanisms to be considered efficient, namely:

1. MAE: Mechanism allocative efficiency: the requirement that the mechanism maximizes social welfare. This condition assures that the use of the mechanism is optimal in the sense that its use does not result in social welfare loss;

2. SOE: Solution efficiency: the requirement that the solution that is the result of the mechanism usage is efficient. This condition is the specific instance of the allocative efficiency; and

3. OCM: The owner's criterion maximization: the requirement that the mechanism results in the solution that is the best possible for the owner, namely the organizations that set the mechanism up and invites others to voluntarily use it in an exchange process. This condition means that the mechanism's users have incentives that lead them to propose solutions that favor the owner leading to the final (winning) solution that is the best the owner could achieve in the particular circumstances.

Auctions in which the sole criterion is price or any other single and linear measure may meet the above conditions providing that the participants are risk-neutral. However, in many B2B and G2B auctions over production goods and services the evaluation criteria are more complex. These criteria include multiple attributes, which may be different for the 
bid-taker and the bid-makers. In fact, surveys of procurement managers as well as field studies find that procured goods (i.e., products and services) are described by price as well as non-price attributes, which range from 2 to 30 [7-10]. In addition, one may argue that in procurement undertaken by public organizations attributes which describe changes in the society's well-being caused by contracting and its implementation should be considered. An example of such a consideration is $\mathrm{A}+\mathrm{B}$ bidding discussed in Section 2.

The use of multiple attributes does not necessarily imply that price-only auctions cannot be effectively used in $\mathrm{B} 2 \mathrm{~B}$ and G2B auctions. It does however, raises a question about their appropriateness, in particular, about auctions being able to meet the above key conditions: MAE, SOC and MOC. Given that auctions are used in transactions amounting to billions, their potential inefficiency is of great importance to public and private organizations.

The purpose of this work is to discuss single and multiattribute auctions conducted in B2G and G2B exchanges and to show that in many situations auctions may result in the winning bid which is an efficient solution (SOE condition) but they are allocative inefficient mechanisms (i.e., they violate AEM condition). Furthermore, we show that if the two assumptions underlying - which is likely in real-life situations - then the winning bid may be replaced with a solution which improves both the bid-taker's and the bid-maker's criteria.

There are three more sections in the paper. In Section 2 we formulate formal conditions that are required for multi-attribute auctions to produce better results than one-attribute auctions. In Section 3 the discussion of two underlying assumptions of auction theory is contrasted with the assumptions' implications and their limitations in real-life auctions. Section 4 concludes with a brief discussion of a process that can be used to transform auctions to hybrid mechanisms which would yield higher utility for the bid-takers (owners) and higher social welfare.

\section{ONE-, TWO-, AND MANY-ATTRIBUTE AUCTIONS}

In many auctions, including procurement auctions, bidders submit only price. There are also auctions in which bids are vectors of multiple attributes. In this section price-only auctions are briefly discussed followed by a discussion on twoand more-attribute auctions. Two-attribute auctions are distinguished because they are simple to use and seemingly assure bid-takers that they obtain goods at the lowest price.

\section{A. Bidding on price}

Many procurement contracts are awarded to qualified bidmakers who offer the lowest price and who can meet the delivery time and other pre-specified conditions. There are also many auctions which do not result in a contract. These auctions are used to determine price and are followed by negotiations [11]. The reason for the auction-followed-by-negotiation mechanism and buyer-determined auctions is that the auction theory and the results from the experimental economics are difficult to implement in procurement [12].

Nelken [13], a spokesperson for the Polish General Direc- torate of National Roads and Motorways (GDNRM) observes: "If all conditions stated in the contract are met, the price is the best criterion for contractor selection." This is the case if the bid-taker uses only price as the criterion for the good's assessment. In reality, often the attributes which values are given to the bid-makers are criteria rather than bounds. For example, GDNRM prefers shorter road completion time than longer and longer warranty period than shorter. The use of price-only auction in which bidders must observe the conditions does not allow the bid-makers to compete on non-price attributes.

If there are more than one attributes that the bid-taker uses, then the imposition of constraints on the good's attributes, other than price, is insufficient to claim that the winning bidmaker offers the best contract.

\section{B. Two-attribute auctions}

Two attribute auctions increase the exchange flexibility because the bid-makers can tradeoff value of one attribute against the second attribute value. They may also be necessary when the bid-taker is obliged to or wants to obtain a contract which optimizes two rather than one criteria. In order to show that in this case two-attribute may produce results that are superior to a single attribute auction.

Let:

$x_{1} \geq 0$ be the price attribute and $x_{2} \geq 0$ - the second (nonprice) attribute;

$u_{b}(\boldsymbol{x})$ (where $\boldsymbol{x}=\left[x_{1}, x_{2}\right]$ ) be the assessment function of the bid-taker $b$ which $b$ wants to minimize, i.e., it is preferable that both $x_{1}$ and $x_{2}$ take low values.

In real-life auctions $u(x)$ is often a linear function, i.e.,

$$
u(x)=x_{1}+a \cdot x_{2},(a>0) .
$$

Let's now consider two bid-makers $s 1$ and $s 2$ who have different capabilities. Assume that the best bid of $s_{1}$ is $\left(x_{1}^{s 1} ; x_{2}^{s 1}\right)$ and $s_{2}$ 's best bid is $\left(x_{1}^{s 2} ; x_{2}^{s 2}\right)$, and $x_{1}^{s 1}<x_{1}^{s 2}$. Bid-maker $s_{1}$ wins the price-only auction. If

$$
x_{1}^{s 1}+a \cdot x_{2}^{s 1}>x_{1}^{s 2}+a \cdot x_{2}^{s 2},
$$

then $s_{2}$ wins the two-attribute auction. This means that the higher price offered by $s_{2}$ is offset by the lower value of the second attribute weighted by $a$, i.e.,

$$
x_{1}^{s 1}-x_{1}^{s 2}>a \cdot\left(x_{2}^{s 2}-x_{2}^{s 1}\right) .
$$

Condition (1) corresponds to a well-known and observed in practice situation when price leaders may be unable to provide goods or deliver them in a shorter time than suppliers who charge higher price.

The gains for the bid-taker in two-attribute auctions over the price-only auctions have been confirmed experimentally [14]. Although in experimental settings these gains were found to be modest, in the comparison of real-life auctions these gains have been found significant. Lewis and Bajari [15] studied over 1300 hundred contracts awarded by the California Department of Transportation, through one- and two-attribute auctions. The two-attribute auctions where of the $\mathrm{A}+\mathrm{B}$ 
type, where A represents price and B represents the total number of days required to complete the contract weighted by the user cost, which is the cost incurred by the road users who have to take alternative routes. Lewis and Bajari used structural analysis to estimate the counterfactual welfare gain from switching from $\mathrm{A}$ (price-only) to $\mathrm{A}+\mathrm{B}$ (price and social costs). They report that this gain represents almost $22 \%$ of the total contract value of $\$ 1.14$ billion. In addition, the contracts were completed $30-40 \%$ faster. These are significant savings for the bid-takers; as of 2003, 38 U.S. states were using auctions with scoring functions for large projects [16].

Lewis and Bajari [15] made another important observation. In both one- and two-attribute auctions the same businesses participated and many of them won both types of auctions. Although the winners were paid about $7 \%$ more in two-attribute as opposed to one-attribute auctions, the bid-takers' savings greatly exceeded these additional costs. Another observation is that the contractors (bid-makers) are able to be significantly more efficient when they have an incentive to do so. From the social perspective this is a significant result because in this way public organizations can not only reduce their total costs but they can contribute to the overall efficiency increase of the industry.

\section{Multi-attribute auctions}

The superiority of the results obtained through two-attribute rather than one-attribute auctions can be extended to exchanges characterized by multiple attributes. Several multiattribute auctions are discussed in literature. Hohner, Rich et al. [17] discuss an electronic private exchange established by Mars Inc., in which volume discount bidding and multi-attribute bidding were used most often.

The attributes that were used in the auctions included payment terms (e.g., pre-payment, payment date, and discount) as well as turnaround time, delivery schedule, product quality, type of material, and color.

Trade Extensions (TradeExtensions.com) offers a procurement software platform which includes reverse auctions. A review of four procurement case studies (i.e., Ineos, Road resurfacing, Elderly Care Services, and Cleaning Services) shows that Trade Extension's uses a full costing process in which all attributes must be expressed in monetary terms. The focus is on the minimization of the costs of procured services subject to constraints imposed on the attributes and their combinations.

It has been recognized recently that public organizations ought to base their procurement decisions on multiple attributes and that this should be made explicit to their suppliers. The European Union has adopted a new public procurement directive, which requires that the procurement authority publish ex ante relative weighting of each criterion. The E.U. directives (Article 55 in 2004/17/EC or Article 53 in 2004/18/EC) require that public contracts be allocated by competitive bidding. The buyer has to either use a scoring function, in which price and other attributes and their weights are given, or a lexicographically ordered list of attributes. In Poland, some of the road construction auctions are still awarded solely based on price [13] but many of these auctions resulted in contractors' bankruptcy [18]. This may be one reason for the introduction attributes additional to price, such as completion time and warranty period [19].

\section{THREE CRITERIA}

All cases discussed in the preceding sections concern products and services that will be produced and delivered in the future. This characteristic must be contrasted with situations in which auctions are over earlier produced goods. The difference is that in post-auction, manufactured products and services can be customized to meet specific needs of the bid-takers. This can be exemplified with the $\mathrm{A}+\mathrm{B}$ auctions discussed in Section 2.2 in which bid-makers increased price on average by $7 \%$ in exchange for the reduction of the contract fulfilment time. This may be seen as a standard business practice as it brings increase of quality, shortening of delivery time, and addition of more features, however, production costs are increased and thus the tree conditions formulated in Section 1 are violated.

\section{A. Two assumptions and their implications}

In Section 1 the three key conditions (i.e., MAE, SOC and OCM) for efficient exchange mechanisms were formulated. Auctions meet all the conditions if the following two assumptions about the bid-makers and bid-takers are met $[20,21]$ :

1. The bid-maker and the bid-takers are risk neutral; and

2. The bid-maker and the bid-takers employ an evaluation functions (e.g., utility, profit, and value functions) which are quasi-linear.

Attitude towards risk influences, among others, the way payoffs are considered. For a risk-neutral person every unit of money has the same value (irrespectively if it is one unit more or less) as long as there is no difference in risk associated with getting more (less) of units. If both bid-takers and bid-makers are risk neutral, then they have the same assessment of the price. If however, their risk attitudes differ, then the same price level will be seen differently.

Violation of risk-neutrality causes that the market participants' utility is not quasi-linear however, this is not a sufficient condition. Quasi-linearity means that that the market participants' utility is the sum of price (i.e., the numeraire) and the valuation function of all non-price attributes. The valuation function is strictly convex and twice differentiable (Varian 2010). The implication of the quasi-linearity assumption is that the valuation function is can be expressed in monetary terms.

Attitude towards risk: and the price cannot be separated from valuation [21, pp. 32-41]. The assumption that participants are risk neutral is often unrealistic; risk aversion has been used to explain overbidding behavior [22]. In procurement auctions, sellers of timber and construction firms were found to be risk averse [23, 24]. Procurement managers in public organizations were found more risk averse than their counterparts in private organizations [25]. (The risk neutrality 
assumption is required in both price-only and multi-attribute auctions.)

Buyers who base their purchasing decisions on the longrun price and other direct and indirect costs or on the total cost of ownership (TCO) model, consider many attributes. The middle- or long-term perspective lends itself to associating money with time, which includes future interest paid and various types of risk (e.g., delayed or not delayed payment, litigation, and change in interest). Because different participants are likely to have different financial, market and production constraints their preferences over money may also differ.

Quasi-linearity utilities: Quasi-linearity is a strong assumption and not particularly realistic [26, p. 63]. Ausubel and Milgrom [27, p. 24] note that the assumption is very restrictive and "requires that there is no effective budget limit to constrain the bidders and that the buyer, in procurement auction, does not have any overall limit on its costs of procurement. Although we have no data on how frequently these assumptions are satisfied, it appears that failures may be common in practice."

When market participants' utilities are quasi-linear, then the efficient transactions, i.e., these that lie on the contract curve of a bid-taker and a bid-maker differ in price value but not in the configuration of attribute values [28]. This may be difficult to accept when the auction is not over goods produced earlier (in which case their costs are fixed) but over goods that are produced only after the auction successfully concludes. Other limitations include such requirements as: (1) the preferential order of attribute values has to be opposite for the bid-taker and the bid-makers; there may not be constraints which bind efficient solutions; and (3) price has to be either a single attribute or a sum of price attributes with exactly the same weights for the bid-taker and the bid-makers [29].

\section{B. Convex/concave utilities of buyers and/or sellers}

Given the above, we may assume that many market participants' utilities are not quasi linear and that they are not riskneutral. The implication of this assumption is that the auctions with risk seeking or risk averse participants do not meet at least one of the mechanism efficiency condition. One may argue that private businesses, who are bid-takers, may not be concerned with the condition violation as long as the OCM condition is met, i.e., the winning bid maximizes their utility. This argument may be questioned when the bid takers are public organizations which should be concerned with the efficient use of resources (SOE condition) and maximization of social welfare (MAE condition).

If the utilities are convex or quasi-convex or, more generally, if the efficient frontier for the bid-taker and the winning bid-maker is concave, then the OCM and MAE conditions may not be met. In such situation the winning bids may be efficient solutions but they can be improved for both the bidtaker and the winning bid-maker. This is because concave efficient solutions create an opportunity to introduce trade-offs which increase utility value of both of them. This potentially significant situation is illustrated in Figure 1.

Consider a winning bid $(A)$; it is a winning bid for both quasi-linear utilities, its efficient frontier is shown by a broken line, and utilities for which the efficient frontier is concave. Let's assume that seller $i$ is the winner and the winning bid is point $A$. If the preferences are quasi-linear, then $A$ maximizes both the buyer's surplus and social welfare. If the efficient frontier is concave, then $A$ does not maximize social welfare; both $B$ and $D$ yield a higher social welfare than $A$.

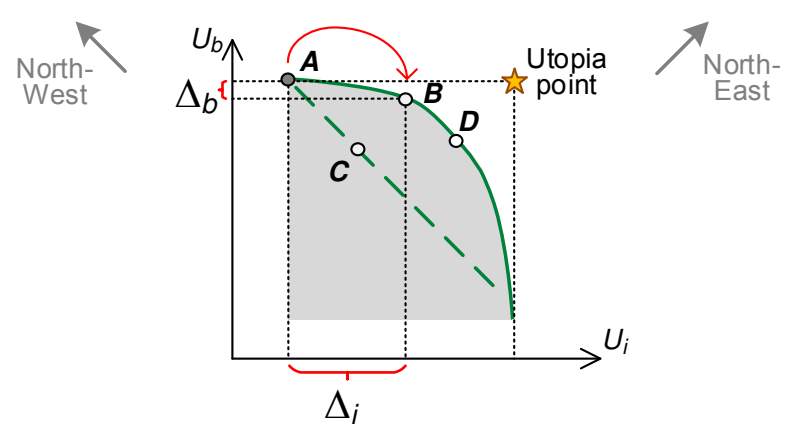

Figure 1. Improvement of the winning bid for concave efficient frontier

Market participants who want to maximize social welfare need to move in the North-East direction. Sellers, who are pushed by competition to increase the buyer's surplus, move in the North-West direction. Quasi-linear preferences together with the use of the sum of utilities as the measure of social welfare, remove the conflict in directions because the North-West moves do not change the distance from the Utopia point ( $\max u_{b}$; $\max u_{i}$ ). However, market participants should be aware of the conflict as it arises when other types of preferences and/or other welfare measures are deemed more suitable.

The alternatives shown in Figure 1 have the following coordinates $\left(u_{b}, u_{i}\right): A=(17 ; 3) ; B=(16 ; 11) ; C=(12 ; 7.5)$; and $D=(13 ; 14.5)$. If we move from $A$ to $B$, then social welfare increases from 20 to 27 , i.e., by $35 \%$. The maximum social welfare is 27.5 and it is reached at alternative $D$. This simple example illustrates that the difference in social welfare value may be significant.

Moreover, reaching a solution which is better than the winning bid may be possible. This, however, requires moving beyond the initial problem formulation. Let's assume that $u_{b}$ and $u_{i}$ are both expressed in monetary terms. We can see that the move from $A$ to $B$ results in buyer $b$ 's loss $\left(u_{b}(A)-u_{b}(B)\right)=$ $\nabla_{b}=\$ 1$ and seller $i$ 's gain $\left(u_{i}(B)-u_{i}(A)\right)=\nabla_{i}=\$ 8$. If buyer $b$ realizes the differences between the winning bid $A$ and the alternative $B$, then she could suggest selecting alternative $B$ under the condition that $i$ pays her $\$ 5$ (or some other amount, which exceeds $\$ 1$ ).

When the utilities are not quasi-linear, then price transfer affects welfare. These utilities may also be assumed to be transferable (this assumption is often made in economics). If the amount to be transferred is positive, i.e., $\nabla_{i}-\nabla_{b}>0$, then the winning bid $A$ may be improved. 
When the efficient frontier is concave, the move from the winning bid ( $A$ in Fig. 1) to a bid that increases social welfare $(B)$ involves a transfer which is similar to price transfer when the frontier is linear with -1 slope, except for the following three differences:

1. Both price and configuration are included in the transfer and in social welfare calculation;

2. The transfer of value from the seller to the buyer requires a change of the configuration; and

3. The value transfer improves the buyer's and the seller's surplus as well as the social welfare.

Value $\theta$ that is transferred to the buyer has to be greater than the buyer's loss (i.e., $\theta>\nabla_{b}$ ). The difference between seller's $i$ gain and buyer's $b$ loss, i.e., $\nabla_{i}-\nabla_{b}>0$, corresponds to the social welfare increase. Assuming that the concavity of the efficient frontiers for the pairs buyer ${ }^{-}-\operatorname{seller}_{i}(i \in I)$ is given and does not change, the size of the transferable value $\left(\nabla_{i}-\nabla_{b}\right)$ can be viewed as the "value of competition". This is because the stronger the competition the greater the buyer's surplus, that is, the winning bid is further from the solution maximizing social welfare. To ascertain this let's denote the concave efficient frontier as function of $u_{i}$, i.e., $v_{b}\left(u_{i}\right)$ and assume that $v_{b}\left(u_{i}\right)$ is twice differentiable. We also assume that the buyer's utility produced by the winning bid is not smaller than the utility which maximizes social welfare.

Given concave efficient frontier, the greater the utility value of the buyer for the winning bid, the greater the transferable value $\left(\nabla_{i}-\nabla_{b}\right)$. Function $v_{b}\left(u_{i}\right)$ is concave, therefore its second derivative is non-positive $\left(v{ }_{b} \leq 0\right)$. This means that the rate of increase of $v_{b}\left(u_{i}\right)$ decreases with the increase of $u_{i}$. Conversely, the rate of increase of $v_{b}\left(u_{i}\right)$ increases when $u_{i}$ decreases. In other words, a small change in $u_{i}$ causes an increasingly greater change in $v_{b}\left(u_{i}\right)$ as $u_{i}$ gets smaller.

\section{AUCTIONS AND MULTI-BILATERAL NEGOTIATIONS}

A concave efficient frontier is the result of convex utilities. Also pairs of linear utilities defined over a convex set of feasible alternatives form a quasi-concave frontier under the condition that different attributes are more important for the participants [30]. In this case, the auctions which have been discussed in literature, are likely allocative inefficient mechanisms, i.e., they do not maximize social welfare. This may result in an efficient solution that maximizes the bidtaker's surplus. However, it may be possible, as the discussion given in Section 3.2 indicates, to improve this solution for both the buyer and the seller.

The competitive force pulls the bid-makers towards the maximum value of the bid-taker utility. If the efficient frontier is concave, then we should consider the winning bid as a tentative but not the final solution. Rather than conclude the exchange, the participants may continue and seek win-win solutions as shown in Figure 1 (points B and D). In this later phase negotiation may be preferable because the bid-taker needs to get involved and propose potential alternatives as well as the required compensation.
Kersten, Wachowicz et al. [31] discuss a multi-bilateral negotiation procedure with verifiable and non-verifiable offers. The procedure is implemented in the Imbins system which is a multi-bilateral negotiations support system, however, it also allows running auctions. This is because in the verifiable offer option the best bid is automatically displayed to all bid makers. This allows the bid-taker to announce the auction rules to all participants at the beginning of the process and then withhold her participation until a winning bid is obtained. After the auction concludes successfully the bid taker reviews the alternatives, namely the bids preceding the winning bid, and selects one or more of them. For every selected alternative she determines the minimum compensation. The compensation is required in order to compensate the bid-taker for the loss she would incur if the winning bid was replaced with the selected alternative.

The determination of the type of the compensation may require that the bid-taker discusses the issue with the bid-makers because it is likely that it concerns attributes which were different from those which were used in the bidding process. When the compensation is established, the bid-taker determines the values associated with each alternative and submits these pairs for the bid-maker's consideration. This may initiate an auction or a negotiation process which, if successful, results in a solution that is better for both the bid-taker and one of the bid-makers.

The Imbins system, which provides verifiable offers, was experimentally compared with a multi-attribute auction system Imaras (Kersten, Wachowicz et al. [31]. The results show that some of the experiment participants (bid-takers) initially used Imbins as an auction system and subsequently became involved and negotiated with their counterparts (see Apendix A for a screen shot). Other bid-takers may have ignored the fact that the best offer (bid) they received was displayed to every bid-maker and they used Imbins as a negotiation support system. In effect, the bid-makers who used Imaras (see Apendix B for a screen shot) achieved significantly lower profit than those who used Imbins. On the other hand, the bidtakers' profit was significantly higher in Imaras than in Imbins. This is despite the fact that in both systems the bid-makers received the same the verified information.

This result shows that the bid-taker's active participation causes them to accept solutions that are worse when they do not participate in the exchange process. The likely explanation can be found in the reciprocity theory which posits that peoples' social upbringing leads them to reciprocate to both positive and negative acts made by other people [32]. Thus, when the bid-makers make concessions, then the bid-takers reciprocate and also make concessions. We conclude that reciprocity in multi-bilateral negotiations weakens the competitive forces and they are left intact in auctions.

Other results of the Imbins and Imaras comparative studies experimentally confirm the propositions made above. Social welfare obtained in verifiable negotiations significantly exceeds welfare obtained in auctions. More importantly, the potential improvement of the negotiated contracts is not only 
significantly greater than contacts obtained through auctions but it is greater than the average welfare of the efficient solutions that dominate the contracts from auction. Social welfare in auctions can reach 42 monetary units (m.u.) on average while social welfare in the negotiations can reach 120 m.u. The difference of 78 m.u. can be distributed between the bidtaker and the winning bid-maker making then both better in negotiations than in auctions. Even if the auction winner receives revenue 0 m.u. and the bid-taker gets 42 m.u., they both lose compared to the bid-maker who gets 50 m.u. and the bidtaker who gets 70 m.u.

\section{WINNERS AND LOSERS}

In many procurement exchanges, both buyers and sellers make decisions based on many attributes rather than price only. A review of recent studies on single- and multi-attribute auctions indicates that multi-attribute auctions produce better results for both the bid-takers and the bid-makers than a single-attribute auction. When, however, multi-attribute bid evaluation functions are used (e.g., utility, profit, and total cost of ownership), then these functions are likely to violate the two key auction theory assumptions. These assumptions assure that auctions are efficient mechanisms, which allow maximization of the social welfare. They also allow maximization of the bid-takers' criterion.

We showed that if the "bid-taker and bid-maker" pairs of the evaluation functions form a quasi-concave efficient frontier, then the winning bid does not maximize social welfare. This means that, in these situations, auctions are not efficient exchange mechanisms. This is an important conclusion for public organizations because their mission is not limited to achieving the best deal for them but which is detrimental to the socio-economic growth. Public organizations may present these winning deals as the most economic (e.g., the cheapest), but this would be a narrow myopic perspective. Their stakeholders, that is society, are the losers. In extreme cases, these loses may be due to the contractors' bankruptcies and foreclosures. In less severe situations, the contractors loses lead to unemployment and underutilization of resources.

When the efficient frontier is concave, the winning bid may be improved not only for the winning bid-maker but also for the bid-taker. The improvement is possible even if the bid is efficient. Given that the bid-maker compensates the bid-taker for the loss, the bid-taker may accept an efficient alternative which is significantly better for the bid-maker than the winning bid. This means that the bid-taker who accepts the auction's winning bid loses because he/she could achieve a better bid. This result is important for both public and private organizations because they forgo the possible improvement. It is also important for suppliers (bid-makers) who could get better contracts than the contracts specified in the winning bids.

\section{ACKNOWLEDGMENTS}

We thank Margaret Kersten, Norma Paradis and Bo Yu for their contribution to the system design and experiment organization.

\section{REFERENCES}

[1] Kaufmann, L. and C.R. Carter, Deciding on the Mode of Negotiation: To Auction or not to Auction Electronically. Journal of Supply Chain Management, 2004. 40(2): p. 15-26. DOI: $10.1111 /$ j.1745-493X.2004.tb00166.x

[2] Schoenherr, T. and V.A. Mabert, Online Reverse Auctions: Common Myths versus Evolving Reality. Business Horizons, 2007. 50(5): p. 373-384. DOI: 10.1016/j.bushor.2007.03.003

[3] Smart, A. and A. Harrison, Reverse Auctions as a Support Mechanism in Flexible Supply Chains. International Journal of Logistics, 2002. 5(3): p. 275-284. DOI:10.1080/1367556021000026718

[4] Bajari, P. and G. Summers, Detecting collusion in procurement auctions. Antitrust LJ, 2002. 70: p. 143.

[5] Perreaux, L. and R. Seguin, Montreal Mafia controls 80 per cent of road contracts, whistleblower says, in The Globe and Mail2009: Toronto.

[6] Bulow, J. and P. Klemperer, Auctions versus Negotiations. American Economic Review, 1996. 86(1): p. 80-194. DOI: 10.3386/w4608

[7] Ferrin, B.G. and R.E. Plank, Total Cost of Ownership Models: An Exploratory Study. Journal of Supply Chain Management, 2002. 38(3): p. 18-29. DOI: 10.1111/j.1745493X.2002.tb00132.x

[8] Plank, R.E. and B.G. Ferrin, How manufacturers value purchase offerings: an exploratory study. Industrial Marketing Management, 2002. 31(5): p. 457-465. DOI: 10.1016/S0019-8501(01)00161-4

[9] Gupta, D., E.M. Snir, and Y. Chen, Contractors' and Agency Decisions and Policy Implications in A+B Bidding. Production and Operations Management, 2014: p. (in print).

[10] Iimi, A., Multidimensional auctions for public energy efficiency projects : Evidence from the Japanese ESCO market, in Policy Research Working Paper 2013, The World Bank. p. 47.

[11] Engelbrecht-Wiggans, R., E. Haruvy, and E. Katok, $A$ Comparison of Buyer-determined and Price-based Multiattribute Mechanisms. Marketing Science, 2007. 26(5): p. 629-641.

[12] Aloini, D., R. Dulmin, and V. Mininno, E-reverse Auction Design: Critical Variables in a B2B Context. Business Process Management Journal, 2012. 18(2): p. 3-3. DOI $10.1108 / 14637151211225180$

[13] Nelken, U. GDDKiA: Zarzuty NIK sq bezpodstawne. 2013 [cited 2014 Apri 15]; Available from: http://forsal.pl/artykuly/702197,gddkia_zarzuty_nik_sa_bezp odstawne.html.

[14] Bichler, M., An Experimental Analysis of Multi-attribute Auctions. Decision Support Systems, 2000. 29(3): p. 249268. DOI: $10.1016 / \mathrm{S} 0167-9236(00) 00075-0$

[15] Lewis, G. and P. Bajari, Procurement Contracting with Time Incentives: Theory and Evidence. The Quarterly Journal of Economics, 2011. 126(3): p. 1173-1211.

[16] Asker, J. and E. Cantillon, Procurement when Price and Quality Matter. The RAND Journal of Economics, 2010. 41(1): p. 1-34. 
[17] Hohner, G., et al., Combinatorial and quantity-discount procurement auctions benefit Mars, Incorporated and its suppliers. Interfaces, 2003.33(1): p. 23-35.

[18] Majszyk, K. Plaga upadtości wśród wykonawców autostrad to wina GDDKiA. 2013 [cited 2014 Apri 15]; Available from: http://forsal.pl/artykuly/702992,plaga_upadlosci_wsrod_wyk onawcow_autostrad_to_wina_gddkia.html.

[19] Majszyk, K. Nowatorski pomyst GDDKiA: premie za autostrady przed czasem. 2013 [cited 2014 Apri 15]; Available from:

http://forsal.pl/artykuly/672280,nowatorski_pomysl_gddkia premie_za_autostrady_przed_czasem.html.

[20] Handfield, R.B. and S.L. Straight, What Sourcing Channel is Right for You? Supply Chain Management Review, 2003. 7(4): p. 63-68.

[21] Krishna, V., Auction Theory. 2010: Academic Press.

[22] Bajari, P. and A. Hortacsu, Are Structural Estimates of Auction Models Reasonable? Evidence from Experimental Data. Journal of Political Economy, 2005. 113(4): p. 703741. DOI: $10.1086 / 432138$

[23] Athey, S. and J. Levin, Information and competition in US forest service timber auctions. Journal of Political Economy, 2001. 109(2): p. 375-417. DOI: 10.3386/w7185

[24] Campo, S., Risk Aversion and Asymmetry in Procurement Auctions: Identification, Estimation and Application to Construction Procurements. Journal of Econometrics, 2012. 168(1): p. 96-107. DOI: 10.1016/j.jeconom.2011.09.011
[25] Boyne, G.A., Public and Private Management: What's the Difference? Journal of Management Studies, 2002. 39(1): p. 97-122. DOI: 10.1111/1467-6486.00284

[26] Varian, H.R., Intermediate Economics. A Modern Approach. 8 ed. 2010, New York: Norton.

[27] Ausubel, L.M. and P. Milgrom, The Lovely but Lonely Vickrey Auction, in Combinatorial Auctions, P. Cramton, Y. Shoham, and R. Steinberg, Editors. 2006, MIT Press: Boston. p. $17-40$.

[28] Strecker, S., Information Revelation in Multiattribute English Auctions: A Laboratory Study. Decision Support Systems, 2010. 49(3): p. 272-280. DOI: 10.1016/j.dss.2010.03.002

[29] Kersten, G.E., Multi-attribute Procurement Auctions: Efficiency and Social Welfare in Theory and Practice. INFORMS Decision Analysis Journal, 2014: (in print).

[30] Mumpower, J.L., The Judgement Policies of Negotiators and the Structure of Negotiation Problems. Management Science, 1991. 37(10): p. 1304 - 1324. doi.org/10.1287/mnsc.37.10.1304

[31] Kersten, G.E., T. Wachowicz, and M. Kersten. Multiattribute Reverse Auctions and Negotiations with Verifiable and Non-verifiable Offers. in Federated Conference on Computer Science and Information Systems. 2013. Kraków: IEEE.

[32] Cropanzano, R. and M.S. Mitchell, Social Exchange Theory; An Interdisciplinary Review. Journal of Management, 2005. 31(6): p. 874-900. DOI: $10.1177 / 0149206305279602$

APPENDIX

A. Screenshot of an Imbins interface with best offer shown

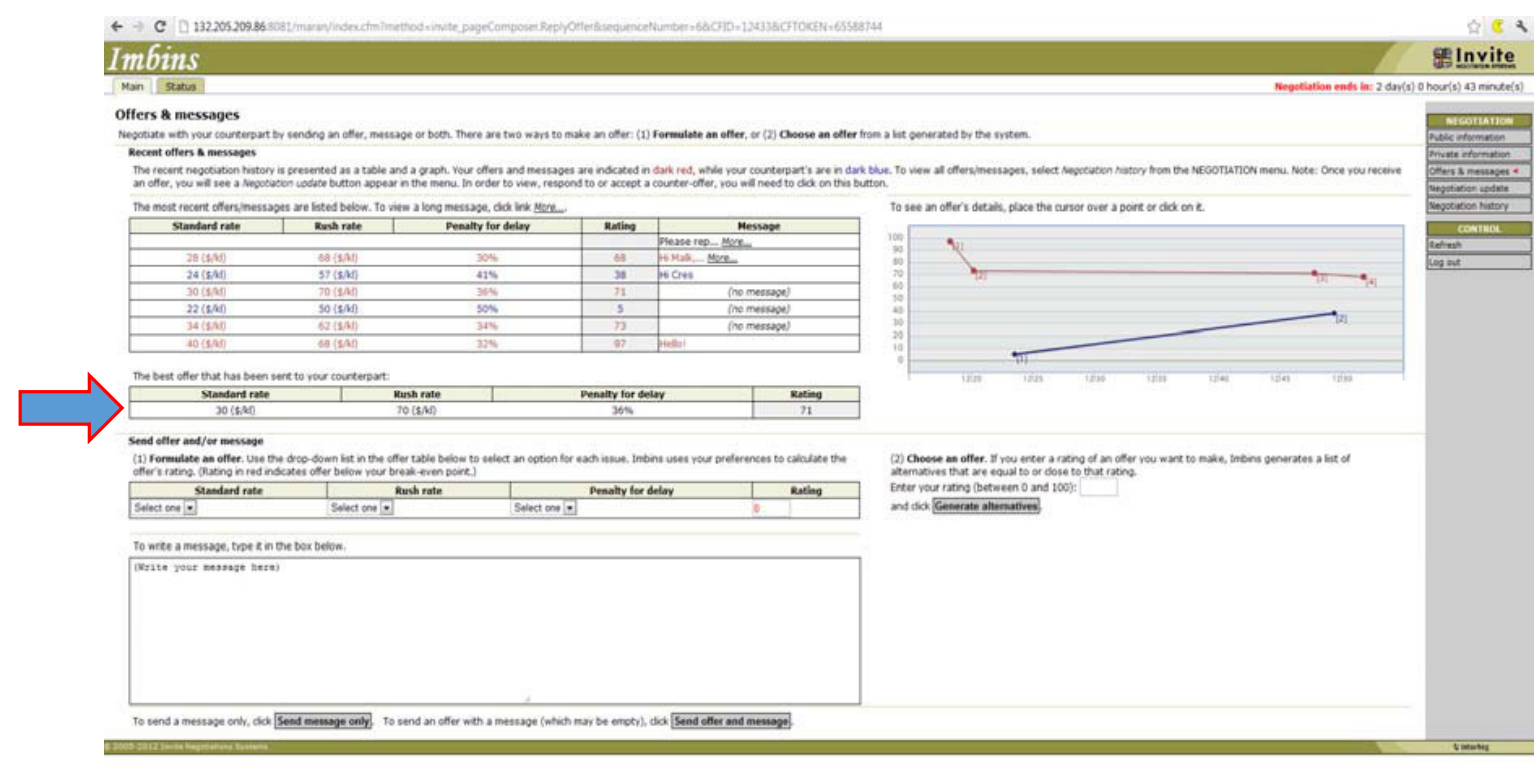




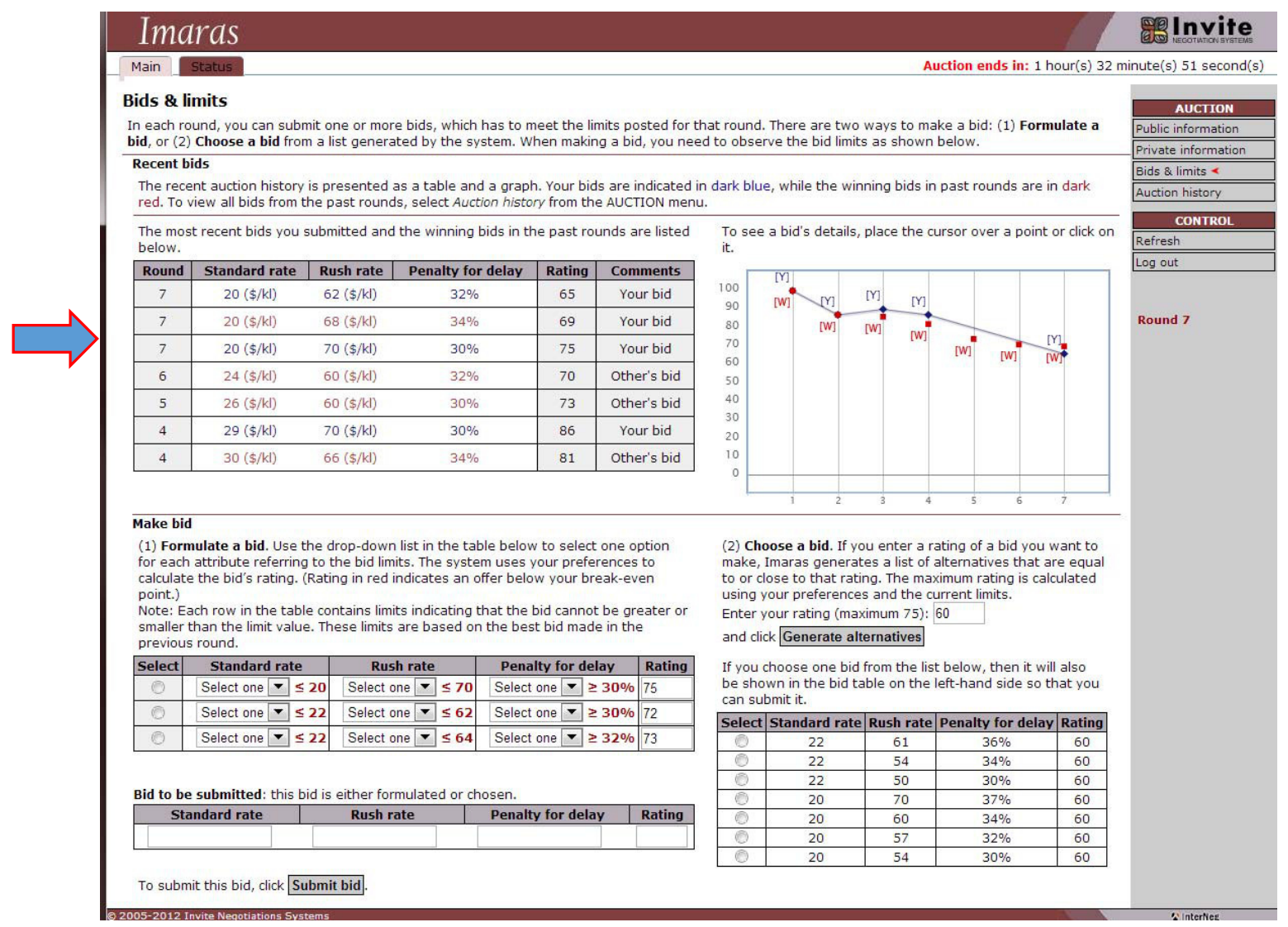

